\title{
AÇÕES EDUCATIVAS EM MUSEUS DE ARTE: ENTRE POLÍTICAS E PRÁTICAS.
}

\author{
Maria Helena Rosa Barbosa \\ Museu de Arte de Santa Catarina (MASC)
}

\section{Resumo}

Este artigo é um recorte de uma pesquisa anterior, concluída no ano de 2009, no qual se apresentam reflexões sobre a função educativa dos museus e as práticas educativas, a partir de alguns documentos oficiais que determinam uma política educacional para os espaços museais, assim como na obra de autores que investigam a educação em museus. Além disso, apresenta-se a análise de algumas questões que permeiam as ações educativas em museus de arte brasileiros.

Palavras-chave

Museus de arte. Ações educativas. Políticas educacionais.

\begin{abstract}
This article is an excerpt from a previous research, concluded in 2009, in which are presented reflections in relation to the educational role of museums and educational practices, based on some official documents that determine an educational policy for the museum spaces, as on studies of authors who investigate education in museums. In addition, it presents an analysis of some issues that permeate the educational actions in Brazilian art museums.
\end{abstract}

Keywords

Art Museums. Educational actions. Educational policies.

\section{Introdução}

Na contemporaneidade, um dos papéis do museu é estar a serviço da sociedade e de seu desenvolvimento. Assim, a função social, atribuída ao museu, potencializa-o como um espaço de comunicação que, por sua vez, dinamiza suas ações educativas, que devem ser pensadas para envolver os diferentes públicos.

Pensar e executar ações educativas são, com efeito, tarefas do educador de museu, que precisa estar inteirado e afinado com os conceitos que permeiam esse espaço, como 
também com as diretrizes estabelecidas pela "Política Nacional de Museus", a fim de que os museus sejam realmente espaços nos quais os cidadãos brasileiros sintam-se estimulados a frequentar e se apropriar de tudo o que eles possam oferecer.

Para provocar a reflexão e apropriação do conhecimento no espaço museal, é necessário que o museu exerça também sua função educativa, pois, como expõe Barbosa (2004, não paginado), "Museus são laboratórios de Conhecimento de Arte, tão importantes para a aprendizagem da Arte como os Laboratórios de Química o são para a aprendizagem da Química". Desse modo, os públicos poderão fazer um bom uso desse laboratório que é o Museu de Arte se forem dadas as condições necessárias. Essas condições dizem respeito a toda a estrutura museológica no exercício das diversas funções atribuídas ao museu, mas principalmente às políticas adotadas por ele, bem como a importância que é conferida, no seu cotidiano, ao caso educacional e investigativo, que é, por si só, uma política.

\section{A função educativa dos museus}

A função educativa dos museus já foi defendida e continua sendo por muitos autores nos mais diversos textos e contextos que a enfatizam em correlação com as suas outras funções, além das de salvaguarda, conservação, exposição e comunicação.

Mário Chagas, no livro Há uma gota de sangue em cada museu: a ótica museológica de Mário de Andrade, publicado em 2006, expõe o resultado de sua dissertação de mestrado, realizada na segunda metade da década de 1990. Nele, Chagas (2006) não só problematiza o desconhecimento do pensamento de Andrade no meio museológico, como também apresenta algumas das ideias do modernista que já eram inovadoras no início do século XX, especificamente no período compreendido "entre 1917 a 1945". Entre as diversas contribuições do pensamento do modernista Mario de Andrade relativas aos seus "projetos políticos culturais", Chagas explica que

Uma destas contribuições refere-se às funções educativas dos museus. Educação museal aqui é concebida não em termos de repetição e inculcação de padrões vigentes como estratégia de reprodução do poder constituído, mas ao contrário, como espaço móvel de estudo, pesquisa e reflexão, como "instrumento capaz de servir às classes trabalhadoras, como instituição catalisadora e ao mesmo tempo resultante da conjugação de forças diversas, como âncora de identidade cultural". (CHAGAS, 2006, p.19). 
Quanto "às funções educativas dos museus", percebe-se, na interpretação de Chagas (2006), que Andrade concebia o museu como um espaço de "estudo, pesquisa e reflexão" e capaz de provocar mudanças na sociedade. Em um fragmento de documento apresentado por Chagas (2006, p.95), é visível a preocupação de Mário de Andrade com o atendimento ao público durante as exposições, bem como com o educador de museu, isto é, ele dizia que as visitas deveriam ser "visitas vivas" e "acompanhadas de explicador inteligente". Com as afirmações anteriores e com outro fragmento de documento citado por Chagas (2006, p.92, grifo do autor) no qual Andrade defende a organização de museus, mas de "museus à moda moderna, museus vivos, que sejam um ensinamento ativo", entende-se a dimensão educativa do museu no pensamento do poeta modernista.

Vale lembrar, ainda, que Mário de Andrade defendia "o uso educativo do patrimônio cultural" por meio de ações que permitissem ao museu ser um agente transformador da sociedade, pois, segundo Chagas (2006, p.91), "O museu concebido por Mário não é apenas um espaço de exposição, é locus de ação".

Em relação à participação ativa do público, Chagas (2006, p.92) explana que, para Mário de Andrade, "[...] o papel do museu não é só o de documentar, mas também o de denunciar, criticar e refletir. É a idéia de Fórum de Debates que ganharia corpo na década de 70 [do século XX]". A pesquisa de Chagas (2006), portanto, muito contribui para a compreensão do pensamento de Mário de Andrade sobre o papel educativo dos museus no Brasil, no início do século $\mathrm{XX}$, e permanece atual, propondo alternativas para problemas ainda presentes em muitos museus, em nosso país.

A função educativa dos museus também foi amplamente discutida no "Seminário Regional da Unesco", em 1958, na cidade do Rio de Janeiro, e que, conforme Araújo e Bruno (1995, p.7), "[...] simboliza paradigmaticamente uma preocupação profissional com a problemática educacional dos museus [...]". Nesse Seminário, segundo Toral (1995, p.9),

O museu deveria desenclausurar-se não somente através de programas didáticos dirigidos à educação formal, como também da utilização de outros meios a seu alcance como o rádio, o cinema, a televisão, para atingir assim camadas mais amplas da população e poder melhor difundir sua mensagem. 
A atribuição ao museu como um agente educativo, na sociedade, possibilitou um alargamento das práticas museológicas, como também uma abertura para a discussão do papel do museu na sociedade contemporânea. Outros documentos fundamentais para compreender os avanços nas discussões sobre as práticas museais são, conforme Araújo e Bruno (1995, p.6),

[...] a Declaração da Mesa-Redonda de Santiago do Chile de 1972, que introduziu o conceito de museu integral, abrindo novas trilhas para as práticas museais; a Declaração de Quebec de 1984, que sistematizou os princípios básicos da Nova Museologia e a Declaração de Caracas de 1992, que poderia ser interpretada como uma avaliação crítica de todo este percurso ao reafirmar o museu enquanto canal de comunicação.

Os referidos documentos consolidam a função educativa dos museus na contemporaneidade e servem de parâmetro para a construção de outros, como a "Política Nacional de Museus - PNM", lançada no Brasil, em maio de 2003, que contou com contribuições da comunidade museológica e representantes de outros segmentos da sociedade envolvidos com as questões pertinentes ao campo museal. Entre as diversas diretrizes apresentadas na PNM, destaca-se, nos "Eixos Programáticos" - seção 2 -, quanto à "Democratização e acesso aos bens culturais", no item 2.4 , o seguinte:

Criação de programas que visem a uma maior inserção do patrimônio cultural musealizado na vida social contemporânea, por meio de exposições, concursos, espetáculos, oficinas e outras ações de caráter educativo-cultural. (BRASIL - PNM, 2003, p.10, grifos nossos).

Nesse sentido, questiona-se: no decorrer desses anos de implantação da PNM - Política Nacional de Museus, o que realmente vem sendo cumprido, ou seja, qual a verdadeira "inserção" dos acervos dos museus de arte "na vida social contemporânea" por meio de "ações de caráter educativo-cultural"?

O caráter educativo dos museus também é apresentado no Decreto $n^{\circ} 5.264$, de 5 de novembro de 2004, que institui o "Sistema Brasileiro de Museus e dá outras providências". Esse, em seu Art. $2^{\circ}$, define que

São características das instituições museológicas, dentre outras:

I - o trabalho permanente com patrimônio cultural; 
II - a disponibilização de acervos e exposições ao público, propiciando a ampliação do campo de construção identitária, a percepção crítica da realidade cultural brasileira, o estímulo à produção do conhecimento e à produção de novas oportunidades de lazer;

III - o desenvolvimento de programas, projetos e ações que utilizem o patrimônio cultural como recurso educacional e de inclusão social; e IV - a vocação para a comunicação, investigação, interpretação, documentação e preservação de testemunhos culturais e naturais. (BRASIL, 2004).

Diante das afirmações nos referidos documentos, percebe-se o quanto as ações do museu devem estar voltadas para o acesso dos diferentes públicos a seu acervo e às suas potencialidades educativas.

Além disso, constata-se que, desde o lançamento da Política Nacional de Museus em 2003, muitas iniciativas têm-se consolidado a fim de garantir a construção de uma política pública na área museológica. Segundo José do Nascimento Junior (2009) ${ }^{1}$, com a aprovação da lei de criação do IBRAM (Lei no 11.906/2009) e da instituição do Estatuto de Museus (Lei no 11.904/2009), acontece "[...] a maior reestruturação na área dos museus [...] no Brasil", pois elas "[...] estruturam o setor museológico brasileiro e colocam o Brasil no mesmo patamar dos países de grande expressão na área museológica". ${ }^{2}$

\section{Práticas educativas em museus de arte}

Ciente da função social e educativa do museu para com a sociedade na qual ele está inserido, bem como dos diversos fatores que contribuem para o êxito das ações educativas no espaço museal, indaga-se: Qual a origem das práticas educativas em museus? Como elas foram desenvolvidas nos museus de arte? Em que medida as práticas contribuem para a aproximação de diferentes públicos com o espaço museal da arte?

\footnotetext{
${ }^{1}$ Foi diretor do Departamento de Museus e Centros Culturais do Instituto do Patrimônio Histórico e Artístico Nacional (DEMU/IPHAN) e, no dia 11 de maio de 2009, foi empossado como presidente do recém-criado IBRAM - Instituto Brasileiro de Museus. Disponível em: $<$ http://www.cultura.gov.br/site/2009/05/12/cerimonia-de-posse-2/ >. Acesso em: 18 jun. 2009.

2 A citação pode ser acessada no site do Ministério da Cultura - MinC. Disponível em:<http://www.cultura.gov.br/site/2009/01/21/presidente-lula-sanciona-criacao-do-instituto-brasileirode-museus-ibram/>. Acesso em: 18 jun. 2009.
} 
Em relação à introdução das práticas educativas nas exposições de coleções dos museus de um modo geral, Nascimento (2005, p.225) comenta que não há um registro esclarecedor sobre sua origem, mas que é possível identificá-la "[...] na organização das visitas orientadas".

No que diz respeito à preocupação com o ensino da arte em museu, Suano (1986, p.39, grifos da autora) lembra, contudo, que

Já em 1857, na Inglaterra, John Ruskin, estudioso de assuntos de arte, apresentara projeto a uma comissão parlamentar para "que se desse uma função mais educativa ao museu: apresentar os objetos com visão crítica e não puramente expositiva".

Nesse sentido, percebe-se que planejar e executar uma ação educativa, dentro de uma visão crítica, não é uma inovação como parece em nossos dias, pois o crítico John Ruskin já fazia tal proposta em 1857.

Em relação a uma abordagem mais crítica no museu para o ensino da arte, Ott (2005, p.116) explana que Henry Cole (1808-1882), primeiro diretor do Victoria and Albert Museum (fundado em 1852, na Inglaterra), revela em seus relatórios que o referido Museu e a Royal College of Art "[...] são os idealizadores dessa relação entre arte na escola e museus de arte [...]". Na proposta em conjunto, os alunos se especializavam em crítica estudando as obras de arte do museu e realizavam o trabalho artístico no ateliê da escola. Diante da afirmação de Ott, percebe-se que, no início da segunda metade do século XIX, o museu já se constituía como um espaço para o ensino da arte, no qual estudantes e educador tinham contato com a obra original para fins de estudo e análise crítica. Ott (2005, p.117) também afirma que as ideias de Cole sobre a importância do museu como instituição voltada para a educação foi "transposta" por seu irmão Charles na "[...] organização do Metropolitan Museum of Art em 1870 [...]" e assimiladas por outros museus, posteriormente fundados nos Estados Unidos.

Lourenço (1999, p.71) relata que o Metropolitan Museum of Art (New York), desde sua criação, em 1870, "[...] organiza um boletim informativo de suas atividades, conferências e exposições, como uma revista voltada ao ensino escolar, de modo a trazer tal público para suas atividades $[\ldots] "$. 
As práticas educativas em museus tornam-se mais consistentes no século $X X$ e os resultados obtidos, principalmente nos museus norte-americanos, exemplos a serem seguidos por outros museus no mundo. Nesse sentido, Ana Mae Barbosa (2005c, p.85) afirma que, com a criação, em 1929, do Museu de Arte Moderna de New York (MoMA), o ensino da arte se constitui como um trabalho "renovador" e de "vanguarda" nas escolas, universidades e no próprio museu, a fim de que as outras classes sociais não pertencentes às elites também pudessem compreender a produção artística moderna. Além disso, ressalta que "[...] os pioneiros da moderna arte-educação em museus [...]" são o MoMA, pautado nas teorias de Victor D'Amico, e o Museu de Cleveland, fundamentado nas teorias de Thomas Munro. E que esses arte-educadores "[...] foram muito influenciados pelas idéias de John Dewey [...]", filósofo e educador americano.

O pensamento de Dewey (1859-1952) exerceu e continua exercendo influências em diversas áreas no campo das ciências humanas. As reflexões sobre questões socioculturais estão presentes em sua obra, assim como a importância da arte para o desenvolvimento humano. Seu texto mais citado no campo do ensino da arte, no Brasil, é Tendo uma experiência, no qual o autor discute o que vem a ser uma "experiência estética". Para Dewey (1974), a experiência estética difere de situações "experienciadas" às quais todos estão sujeitos, pois, para que a experiência seja realmente estética, é necessário que ela seja provida de ação, percepção, reflexão e interação, de forma que o sujeito realize conexões com conhecimentos já aprendidos.

O trabalho de "apreciação de arte", formulado por Thomas Munro (1901-1973), foi realizado no Museu de Cleveland por três décadas. A proposta dele, conhecida como "morfologia estética", consistia em que o aluno observasse atentamente as obras, percebesse como cada obra era constituída, fizesse um esboço a ser desenvolvido no ateliê e conversasse sobre as obras a partir de "formulações críticas". Munro não priorizava a história da arte durante a visita ao museu por considerar que ela poderia ser melhor trabalhada fora dele. Ele também já chamava a atenção para o fato de que as crianças só poderiam entrar em contato com obras de arte se tivessem professores interessados em permitir essa aproximação. Munro ainda definiu em seus escritos "[...] o papel do arte-educador de museu como catalisador, mediador e professor de arte" (OTT, 2005, p.117-119).

Nas ideias de Munro, percebe-se a importância do trabalho anterior e posterior à visita ao museu, assim como do professor como aquele que possibilita o acesso à arte, e do arteeducador de museu como o sujeito que está entre o educando e as obras de arte, 
exercendo um papel de estimulador, provocador e transformador do processo de ensinoaprendizagem.

Nessa breve retrospectiva, pode-se observar que as práticas educativas em museus de arte já apresentavam uma preocupação com o ensino da arte por meio do contato direto com as obras, assim como ao que diz respeito ao trabalho a ser realizado posteriormente à visita. Ressalta-se, entretanto, que o recorte apresentado refere-se apenas às realidades inglesa e norte-americana, pois, possivelmente, a questão possa ser mais explorada em publicações que apresentam outras realidades, às quais não se teve acesso no presente estudo.

\section{Práticas educativas em museus de arte no Brasil}

A relação museu de arte e educação, no Brasil, está associada à origem de alguns museus em espaços de ensino da arte, no século XIX e início do século XX. Essa afirmação pode ser constatada na origem do Museu Nacional de Belas Artes, cuja coleção foi instalada na Academia Imperial de Belas Artes (1843); do Museu de Arte da Bahia, no qual a coleção foi instalada no Liceu Provincial (1871) e, logo em seguida, no Liceu de Artes e Ofícios (1872); e da Pinacoteca do Estado de São Paulo, cuja coleção foi abrigada no Liceu de Artes e Ofícios (1905). Assim, pode-se dizer que essas coleções eram praticamente acessíveis aos estudantes de arte para fins de estudo.

A partir do final da década de 1940, com a criação do MASP (1947), do MAM/SP (1948) e MAM/RJ (1948), é que realmente se encontra um referencial de "experiências educacionais" nos museus de arte, como aponta Lourenço (1999, p.46):

O MASP, o MAM/SP e o do Rio interessam-se por atividades profissionalizantes, dedicando-se aos artistas plásticos e de outras modalidades, tendo também o MAM/SP formado monitores para a bienal e despertado o meio para trabalhos educacionais. O MASP investe em áreas como design e propaganda, e também em monitorias iniciadas por Pietro Maria Bardi e voltadas para o acervo, o que é notável para o meio por gerar familiaridade pela freqüência, como também em aulas pela televisão, contando com a colaboração de Flávio Motta, um professor de gerações de historiadores da arte. ${ }^{3}$

\footnotetext{
${ }^{3}$ Um breve histórico sobre a televisão no Brasil desde sua estréia em 1950 pode ser encontrado em: A História da televisão no Brasil. Disponível em:
} 
Lourenço (1999, p.46) ainda ressalta que a iniciativa educacional ${ }^{4}$ desses museus, abrindo o espaço para o "fazer" em oficinas destinadas ao público infantil, juvenil e adulto ampliou "[...] o público interessado pela arte". Esses museus têm como parâmetro, para as suas atividades, o MoMA como um museu "vivo" e "dinâmico", bem como serão referência para a constituição de outros museus de arte no Brasil, com o objetivo de "disseminar a arte moderna" ${ }^{5}$ pelo país.

No final da década de 1950, especificamente com a criação do Museu de Arte Moderna da Bahia (1959), que contou com desenvolvimento de ações culturais coordenadas por Lina Bo Bardi, é que o museu no Brasil começa a possibilitar uma aproximação maior das classes populares com esse espaço da arte. A respeito de suas ações no MAM-BA, ela assim esclarece:

Comecei o trabalho eliminando a 'cultura estabelecida' da cidade, procurando apoio da Universidade e dos estudantes, abrindo o Museu gratuitamente ao povo, procurando desenvolver ao máximo uma atividade didática. (LINA BO, 1992 apud LOURENÇO, 1999, 183-4).

No MAM-BA, Lina Bo Bardi agrega toda sua experiência anterior, como arquiteta e designer, responsável pelas adaptações da primeira sede do MASP (1947), assim como pela organização de exposições didáticas, pelo projeto arquitetônico e museográfico da segunda sede do Museu $^{6}$, para repensar esse espaço da arte.

$<$ http://www.tudosobretv.com.br/histortv/historbr.htm>. Acesso em: 25 set. 2008.

${ }^{4}$ As ações educativas desses museus, dentro de suas especificidades, podem ser melhor compreendidas a partir do histórico que Lourenço apresenta sobre cada um deles no livro Museus acolhem o Moderno (1999).

${ }^{5}$ Para Lourenço (1999, p.157), Marques Rebelo também foi um grande incentivador da criação de Museus de Arte no Brasil como o de Florianópolis (SC), Resende (RJ) e Cataguases (MG) em 1950.

${ }^{6}$ Sobre as exposições e os projetos de Lina Bo Bardi para o MASP, ver: BARDI, Pietro Maria. História do MASP. São Paulo: Instituto Quadrante, 1992. 
Segundo Lourenço (1999, p.181), Lina Bo Bardi afirmava, em suas entrevistas, que o MAMBA deveria chamar-se "CENTRO, MOVIMENTO, ESCOLA", e que as ideias dela para esse Museu revelam "[...] seu lado mais significativo, como humanista e crítica do aristocratismo e conservadorismo, habituais no trato da cultura brasileira" (p.186).

Como um "centro, movimento, escola" no qual o museu buscava o apoio da universidade e dos estudantes no desenvolvimento de ações, a fim de possibilitar o acesso das classes populares, ele abria-se como um espaço de apropriação do conhecimento para todos. Essa parceria entre universidade e museu é um bom exemplo a ser seguido, hoje, para aproximar as instituições e, principalmente, para juntas produzirem conhecimento e buscarem a solução de problemas; dentre outros, aqueles que dizem respeito à questão do acesso aos diferentes tipos de público no espaço museal.

As ideias de Lina Bo Bardi para o MAM/BA estão em sintonia com o tema do "Seminário Regional da Unesco", que aconteceu em 1958, na cidade do Rio de Janeiro, e no qual a "função educativa dos museus" foi amplamente discutida.

Quanto às fundamentações teóricas das práticas educativas em museus de arte no Brasil nas décadas de 1970 e 1980, Franz (2001, p.44) expõe que,

No Brasil, a arte-educação em museus foi improvisada, com raras exceções, até o final dos anos 70 . Nesse período, os serviços de arteeducação estavam atrelados às influências do ideário da livre expressão que chegaram ao Brasil através do inglês Herbert Read e foram disseminadas pelas escolinhas de arte, de Augusto Rodrigues desde 1948. Nos principais centros culturais do país foi durante os anos 80 que se iniciou uma mudança de postura no enfoque metodológico dessas práticas.

A afirmação de Franz contribui para entender como é tardia, no Brasil, a compreensão dos arte-educadores, que atuam na escola, sobre a importância da visita a museus e dos educadores de museu em fundamentar suas práticas educativas. ${ }^{7}$ É importante salientar

\footnotetext{
${ }^{7}$ O trabalho desenvolvido na Escolinha de Arte do Brasil (1948) exerceu uma forte influência no ensino da arte no país, em caráter ainda experimental nas escolas e posteriormente na formação de professores de arte para atender a demanda após 1971, com a Lei 5692/71. Essa lei determinava que no currículo de $1^{\circ}$ grau (hoje Ensino Fundamental) e em alguns de $2^{\circ}$ grau (atual Ensino Médio) a disciplina de arte fosse obrigatória (na época ainda denominada Educação Artística). Sobre o
} 
que essa situação se deve a toda uma questão política e ideológica que envolve não só o ensino da arte, mas toda a educação no Brasil, conforme se pode constatar em Aranha (1996).

As mudanças no ensino da arte e, por sua vez, nas práticas educativas em museus de arte se dão a partir do final da década de $1980^{\circ}$, por meio da Proposta Triangular, de Ana Mae Barbosa, uma pioneira em defesa da importância do desenvolvimento da cognição na arteeducação, tanto no ensino formal quanto no não formal.

A Proposta Triangular ${ }^{9}$, uma nova abordagem para o ensino da arte no Brasil, foi sistematizada entre os anos de 1987 e 1993, período em que Ana Mae foi diretora do Museu de Arte Contemporânea da USP. A proposta tem como princípio norteador a premissa de que o ensino da arte se dê de modo interligado entre "história da arte", "leitura da obra de arte" e "fazer artístico".

Desde a primeira publicação, em 1991, do livro A imagem no ensino da arte: anos oitenta, a Proposta $\operatorname{Triangular}^{10}$ tornou-se amplamente conhecida e desenvolvida nas escolas e

assunto ver: BARBOSA, A.M. Cronologia da dependência. In: BARBOSA, A.M. John Dewey e o ensino da arte no Brasil. 3.ed. rev. e aum. São Paulo: Cortez, 2001; e ROSA, M. C. da. Um breve histórico do ensino da arte no Brasil. In: ROSA, M. C. da. A formação de professores de Arte. Florianópolis: Insular, 2005.

${ }^{8}$ Segundo Grinspum (2000), as mudanças nas práticas educativas, no Brasil, na década de 1980, também se dão por meio dos princípios da Educação Patrimonial que foi adotada principalmente pelos museus de História. A Educação Patrimonial é fundamentada no trabalho pedagógico Heritage Education, desenvolvido na Inglaterra e introduzida no Brasil em 1983, por Maria de Lourdes Parreira Horta. De acordo com Horta et al. (2006, p.08) "A Educação Patrimonial consiste em provocar situações de aprendizado sobre o processo cultural e seus produtos e manifestações, que despertem nos alunos o interesse em resolver questões significativas para sua própria vida, pessoal e coletiva". Essa provocação se dá por meio da investigação do objeto cultural como "fonte primária" de conhecimento a partir de uma série de "perguntas e reflexões".

${ }^{9}$ A proposta é embasada em três abordagens de ensino da arte, ou seja, das "[...] Escuelas al Aire Libre mexicanas, o Critical Studies inglês e o Movimento de Apreciação Estética aliado ao DBAE (Discipline Based Art Education) Americano" (BARBOSA, 2007, p.33-4).

${ }^{10}$ A proposta também foi disseminada pelo Projeto Arte na Escola (1989) do Instituto Arte na Escola/ Fundação lochpe que a adotou como fundamentação teórica do material pedagógico destinado ao ensino da arte nas escolas. 
museus de arte do país. No referido livro, Barbosa (2005c) também discorre sobre a situação política, conceitual do ensino da arte no país, na década de 1980, e apresenta "diferentes metodologias", com exemplos de "leitura de obra de arte", de diferentes pesquisadores estrangeiros.

Esses exemplos são apresentados de forma a ressaltar a importância do uso da imagem no ensino da arte, em sala de aula, assim como de provocar reflexões no arte-educador sobre o que problematiza uma leitura da obra, ou o que leva a respostas superficiais que não contribuem para uma análise mais crítica.

Embora a Proposta Triangular tenha causado alguns dissabores após sua disseminação, pois foi trabalhada de forma equivocada por alguns educadores ${ }^{11}$, ela apresenta a mudança de paradigma no ensino da arte, isto é, a importância da arte como conhecimento, da "leitura da imagem" e do contato do estudante não só com reproduções de obra de arte, mas também com a obra original, tanto em museus quanto em outros espaços expositivos.

Em revisão posterior sobre os equívocos gerados a partir da Proposta Triangular, no livro Tópicos Utópicos, com primeira publicação em 1998, Barbosa (2007) fala sobre a interpretação reducionista da proposta pelos educadores, ou seja, de "[...] restringir o fazer artístico como releitura"12 (p.40), mais precisamente como cópia. Além disso, entre outras reflexões sobre a proposta, acrescenta que,

\footnotetext{
${ }^{11}$ É importante salientar que o trabalho equivocado a partir da proposta não se deu somente por arteeducadores, mas por outros profissionais em contato com a proposta posteriormente. Em razão dos problemas que dizem respeito à atualização dos educadores no Brasil, pode-se dizer que a proposta foi transmitida como aquela brincadeira "telefone sem fio", que do primeiro ao último chega completamente diferente.

${ }^{12}$ Sobre "releitura", Ana Mae Barbosa diz que o melhor texto que "explicita" o tema é o de Analice Pillar. O texto ao qual ela se refere é "Leitura e releitura" e foi publicado em: PILLAR, Analice Dutra.(Org.). A educação do olhar no ensino das artes. Porto Alegre: Mediação, 1999. O problema da releitura como cópia também é discutido por Anamelia Bueno Buoro no primeiro capítulo de seu livro Olhos que pintam: a leitura de imagem no ensino da arte (2002); e no texto "Releitura, citação, apropriação ou o quê?", de Ana Amália Barbosa publicado em: BARBOSA, Ana Mae. (Org.). Artel educação contemporânea: consonâncias internacionais. São Paulo: Cortez, 2005.
} 
[...] em vez de designar como história da arte um dos componentes da aprendizagem da arte, ampliamos o espectro da experiência nomeando-a contextualização, a qual pode ser histórica, social, psicológica, antropológica, geográfica, ecológica, biológica etc., associando-se o pensamento não apenas a uma disciplina, mas a um vasto conjunto de saberes disciplinares ou não. (BARBOSA, 2007, p.37-8, grifo da autora).

A ampliação para contextualização e o pensamento de Barbosa de que "Contextualizar é estabelecer relações" (2007, p.38) permitem entender a importância da interlocução do ensino da arte com outras disciplinas e de que, para compreender arte, também é necessário estabelecer relações com outros saberes aprendidos na escola ou fora dela.

Pode-se dizer que a Proposta Triangular foi explorada nos museus de arte no que diz respeito à "leitura de imagem" e à "contextualização", no trabalho de mediação entre os públicos e as obras de arte nas exposições, mas o "fazer artístico" não foi desenvolvido com frequência, principalmente naqueles que não dispõem de espaço físico para essa atividade. Hoje, após toda essa mudança no ensino da arte no Brasil, tanto na educação formal quanto na não formal, pergunta-se: o que realmente fundamenta as práticas educativas nos museus de arte? Será que os arte-educadores de museus de arte e da escola, no Brasil, estão atentos às discussões sobre como se ensina e se aprende em museu?

\section{Museu e política educacional}

A discussão em pauta não só no meio museológico, mas também em diversos segmentos da sociedade, é a de como os museus devem exercer uma política educacional, e que estratégia utilizar para desempenhar seu papel de agente transformador da sociedade. Esse papel foi bem enfatizado no "3 Fórum Nacional de Museus", realizado em 2008, cujo tema foi "Museus como agentes de mudança social e desenvolvimento".

Esse tema, certamente, contribui para uma maior ênfase no que caracteriza a compreensão da função primordial do museu que é o seu compromisso com a educação. Cabe lembrar, contudo, que Studart (2004b, p.38) assim esclarece: "Não basta os educadores quererem dar um sentido claro ao seu trabalho, se este não fizer parte de uma política institucional".

A educação, como uma das políticas centrais do museu, também é esclarecida por Santos (2008, p. 141), que assim afirma: 
O que é mais importante compreender é que todas as ações museológicas devem ser pensadas e praticadas como ações educativas e de comunicação, mesmo porque, sem essa concepção, não passarão de técnicas que se esgotam em si mesmas e não terão muito a contribuir para os projetos educativos que venham a ser desenvolvidos pelo museu [...].

Assim, entende-se que não é possível os educadores fazerem um bom trabalho se ele não estiver inserido em um contexto maior de qualidade, e também se compreende o porquê de alguns setores educativos estarem fadados ao isolamento dentro de suas próprias instituições, assumindo uma responsabilidade sobre seus atos, a qual não é sua apenas.

No que concerne às problemáticas que envolvem a educação em museus de arte, Ana Mae Barbosa (2005a) salienta que isso também se deve ao preconceito em relação ao que diz respeito à própria palavra Educação, pois, no campo artístico, principalmente alguns profissionais da área, como professores e artistas-professores de universidades, dizem não entender de Educação. A autora ainda chama a atenção para o fato de que alguns museus e centros culturais, no Brasil, preferem "[...] designar seus departamentos voltados para ensino, divulgação ou extensão [...]" (BARBOSA, 2005a, p.100) com outros nomes que não estejam diretamente associados à palavra Educação. Além disso, afirma que países do primeiro mundo "[...] assumem o papel educacional e a designação educação com orgulho e com a consciência de que a principal função da cultura é educar [...]" (BARBOSA, 2005a, p.101). Diante de tal afirmação, pode-se indagar se o preconceito em relação à educação nos museus de arte não está associado à formação dos profissionais da área de artes visuais que acabam interagindo nesse espaço, como curadores, críticos, artistas e professores.

A publicação Educação em Museus, originalmente editada pelo Museums and Galleries Commission (2001), um órgão britânico, defende que, para que seja garantida a educação nos museus, é fundamental a adoção de uma política educacional escrita e aprovada pelo conselho do museu. Ainda expõe que "[...] cada museu deve procurar maximizar a função educativa de seus acervos e atividades", pois "Exposições e documentação de acervos, por exemplo, têm importante potencial educativo" (p.17). A publicação também sugere que o responsável pelo "programa educativo" seja um especialista em "educação em museus" e participe da "instância diretiva". Assim, entende-se que esse profissional deve participar das discussões do museu e não ser meramente um receptor de decisões. 
Em relação ao envolvimento com esse processo educativo nos museus, Ramalho e Oliveira (2006, não paginado), no texto apresentado na mesa-redonda do primeiro Ciclo "Museu, Educação e Cultura em Debate"13, apresenta uma reflexão acerca de que um museu, voltado para ações que priorizem a "[...] EDUCAÇÃO em sentido amplo [...]" (grifo da autora), não poderia ser um espaço com compartimentação de setores, isto é, que o ideal seria que todos os setores estivessem totalmente envolvidos e articulados entre si na tomada de decisões para exercer uma política educacional, e que,

Por sua vez, essa política seria coerente com uma proposta de aproximar o grande público, da arte, das obras, do artista, por meio do Museu. Assim teríamos uma política educacional, voltada para o acesso de um públicoalvo tradicionalmente excluído dos canais de acesso à arte e a tudo o que ela significa. (RAMALHO e OLIVEIRA, 2006, não paginado, grifos da autora).

A autora, além de enfatizar a importância da interlocução entre todos os atores do espaço museal no que compete pensar a educação no planejamento de todas as suas ações, também aponta duas questões fundamentais para a educação que é a de inclusão e acesso à arte.

O pensamento de Studart (2004b), de Ramalho e Oliveira (2006) e da publicação Museums and Galleries Commission (2001) são, além de coincidentes, fundamentais para quem trabalha na ação educativa de museus de arte e também para todos os funcionários envolvidos com o espaço museal, principalmente para aqueles que exercem cargos de liderança, ou seja, aqueles que decidem as ações e projetos do museu.

Provoca, ainda, algumas reflexões no sentido de questionar o seguinte: como um museu exerce uma política educacional, se não prioriza projetos educativos no planejamento das

${ }^{13}$ O Ciclo "Museu, Educação e Cultura em Debate" foi um projeto realizado em parceria entre a UNESC - Universidade do Extremo Sul Catarinense (Museu da Infância), o Centro de Educação da UFSC - Universidade Federal de Santa Catarina e o MASC - Museu de Arte de Santa Catarina (NAE - Núcleo de Arte-Educação). Aconteceu uma vez por mês, entre os anos de 2006 a 2008. Teve como finalidade possibilitar trocas de experiências entre educadores de museus, de escolas, de universidades e pesquisadores sobre questões que envolvem a educação não formal no espaço do museu. (MUSEU, EDUCAÇÃO E CULTURA EM DEBATE. Florianópolis: FCC/ SC, 2006 [2007, 2008]. Folder-color). 
exposições? Como um museu exerce uma política educacional se não prioriza exposições do acervo em seu planejamento anual? Como se concebe a existência de uma política educacional se o museu não divulga com antecedência às escolas (ONGs, associações e outras instituições) para que possam não só programar a visita em tempo hábil, mas também pensar em projetos a partir do acervo dos museus de arte durante o ano letivo? Para finalizar o rol de questionamentos, indaga-se: como um museu pode promover transformações sociais, incluir e dar acesso se não entende a amplitude do que caracteriza a educação em museus?

\section{Ações educativas em alguns museus de arte brasileiros}

Com o propósito de investigar como as políticas dos museus de arte interferem nas suas ações educativas, realizou-se pesquisa de natureza qualitativa e de caráter documental com museus de arte brasileiros, de diferentes regiões do país (ROSA BARBOSA, 2009). Importa destacar que o estudo originou-se de inquietações nascidas no exercício profissional dentro de um espaço museal da arte. Assim, foram elaborados questionários que foram enviados por meio do correio eletrônico - e-mail - para os setores administrativo e educativo de quinze museus de arte brasileiros.

Portanto, neste recorte, apresenta-se a análise de algumas questões que permeiam as ações educativas de oito museus de arte brasileiros participantes da pesquisa. Informa-se, ainda, que as instituições museais são, por questões éticas, apresentadas por letras do sistema alfabético como Museu: F, H, K, L, E, I, D e G.

As perguntas que correspondem à análise sobre as ações educativas são: Quais são e como se dão as ações educativas no Museu? Que tipo de ações o setor desenvolve? Quais os principais problemas encontrados pelo setor educativo no desenvolvimento de suas ações? O que fundamenta as ações do setor educativo?

Assim, na análise das perguntas referentes às questões pertinentes às ações educativas, constatou-se, a partir das respostas dos Museus F, H, K, L, E, I, D e G, que os setores educativos dos museus desenvolvem diversas ações para diferentes públicos, como a mediação nas exposições, cursos, palestras, entre outros. No entanto, apesar de se perceber que os educadores dos museus participantes da pesquisa têm o entendimento de que as propostas educativas devem ser pensadas para outros grupos, além dos escolares, nota-se que nem todos os museus têm propostas específicas para públicos não escolares, ou seja, para públicos constituídos por famílias, pessoas idosas, pessoas com deficiência, entre outros. Essa constatação se dá porque, ao indagarem-se os setores educativos sobre 
os tipos de ações que desenvolvem, poucos registraram ter programas exclusivamente destinados a esses diferentes públicos. Entre os setores Educativos dos museus que deixaram explícito o trabalho com públicos especiais, destacam-se: o do Museu $\mathbf{K}$ que afirmou realizar mediações com públicos especiais; o Museu $\mathbf{E}$, que destacou, entre as suas atribuições, a de desenvolver projetos educativos para públicos especiais. Quanto a propostas para outros públicos, somente o Museu I registrou realizar atividades para famílias.

Tendo em conta a proposição de ações educativas, tanto para públicos escolares como não escolares, entre eles os públicos especiais, ressalta-se que os museus necessitam de profissionais qualificados, assim como de assessorias de especialistas que orientem o trabalho a ser realizado com cada tipo de público, de acordo com suas especificidades. Além disso, para os educadores de museus proporem ações para os diferentes públicos e trabalharem diretamente com eles, esses profissionais precisam ter, além dos conhecimentos referentes às questões da arte, outros que dizem respeito às particularidades relativas ao comportamento e níveis de compreensão de cada um dos públicos, para que eles tenham não só o acesso cultural, mas também o acesso intelectual a esses espaços da arte.

No que concerne a ações educativas voltadas para famílias, Hooper-Greenhill (1994) enfatiza que os museus devem estar atentos às necessidades desse público potencial, principalmente por serem constituídos por pessoas de diferentes faixas etárias, ou seja, adultos, adolescentes, crianças menores e bebês. A autora destaca, ainda, que os museus dispõem de um grande potencial para que pais e filhos vivam experiências ímpares a partir de conversas sobre temas variados, na qual eles não só aprendem comparando o que já conhecem como também ampliam conhecimentos, juntos, sobre coisas que ainda não conhecem. Assim, Hooper-Greenhill (1994, p.142) propõe que os museus realizem ações educativas para grupos de famílias a partir de desafios para solucionarem juntos, a fim de incentivar a conversação e a troca de ideias, bem como o estabelecimento de relações com o que já conhecem e os novos conhecimentos que estejam se apropriando durante a visita.

Quanto aos principais problemas encontrados pelo setor educativo no desenvolvimento de suas ações, constata-se que eles são similares em alguns casos e diferenciados em outros. O Museu F e o Museu $\mathbf{H}$ destacam a questão financeira, e os Museus F e $\mathbf{L}$ enfatizam os de ordem humana, ou seja, da falta de pessoal permanente do setor educativo, no quadro de funcionários do museu, para realizarem um trabalho de continuidade e não apenas ações pontuais. O Museu D destaca os de ordem financeira e de pessoal, e o Museu I enfatiza o 
espaço físico, como também a resistência dos visitantes na primeira visita. Já o Museu E pontua questões sobre as quais precisa estar constantemente atento e que envolve diretamente sua relação com os visitantes. Essa preocupação do Museu E é fundamental, pois, como os museus oferecem o atendimento às visitas tanto de grupos escolares como de outros grupos, que são agendados por intermédio de agências de turismo, é necessário um contato prévio dos professores ou responsável pelo grupo com os educadores dos museus quanto aos interesses da visita. No que diz respeito à resposta do Museu $\mathbf{K}$, ela se diferencia dos outros ao apontar o problema da política do museu em relação ao seu acervo, como a de não priorizá-lo nos ciclos de exposições e do tempo reduzido de duração, entre "30 a 40 dias", tanto em exposições do acervo quanto de outras temporárias, que acabam por impossibilitar o "planejamento e qualidade desejados nos projetos educativos".

Não só os problemas de ordem financeira ou de pessoal interferem nas ações educativas dos museus, mas também o que diz respeito às políticas do museu em relação ao seu acervo e ao tempo de duração das exposições. Nesse sentido, questiona-se: afinal exposições com pouco tempo de duração são realizadas para quem e para quê? Que públicos exposições de tão pouco tempo atingem?

Nota-se que a instabilidade, na qual os setores educativos trabalham em relação à pauta de exposições dos museus, afeta o desenvolvimento de um trabalho com mais qualidade, pois o tempo exíguo que os educadores têm para se apropriar dos conceitos e conteúdos de uma exposição prejudica o desenvolvimento de projetos que contemplem propostas para diferentes públicos. Além disso, uma das principais ações realizadas pelos setores educativos, que é a mediação entre os públicos e as obras de arte nas exposições, precisa de um tempo hábil de preparação por parte dos educadores, pois não se realiza uma mediação de qualidade sem pesquisa e estudo.

Cabe lembrar que, como é do entendimento dos profissionais no campo das artes visuais, mesmo que uma exposição seja pensada a partir de um conceito, um tema, cada obra de arte é um universo a ser explorado em relação aos elementos intrínsecos a ela, como os formais, cromáticos, espaciais, matéricos e aos efeitos de sentido que ela produz. Esses dizem respeito às relações que podem ser estabelecidas entre uma obra e as outras de uma mesma exposição, a produção artística em distintos períodos, assim como com os saberes sistematizados, provenientes das mais diversas áreas do conhecimento, e com o saberes não sistematizados, oriundos das experiências e vivências cotidianas das pessoas. 
Ainda que se tenha percebido que as ações realizadas pelos setores educativos sejam propostas para aproximar os diferentes públicos da arte, constatou-se que, dos sete museus que responderam o questionário do setor educativo, apenas dois deles revelaram o referencial teórico no qual estão fundamentadas as suas ações. A falta de definição de uma abordagem teórica tornou-se evidente nas respostas da pergunta que indagava sobre o que fundamentava as ações do setor educativo, pois alguns deles entenderam-na como motivo e outros, como teoria. Mesmo aqueles que a interpretaram como teoria, no entanto, não apontaram a abordagem teórica na qual estão pautadas as suas propostas. Dentre eles, apenas o Museu $\mathbf{L}$ disse ser a partir da teoria de Robert Ott, com algumas alterações para a sua realidade; e o Museu D afirmou pautar-se nas teorias de Paulo Freire e de Teresinha Franz.

A proposta de Ott, que visa ao ensino de crítica nos museus, tornou-se conhecida no Brasil quando ele esteve no país, especificamente em 1988, no Museu de Arte Contemporânea da USP, no qual ministrou um curso, bem como distribuiu o texto. Posteriormente, no final da década de 1990, a proposta foi publicada no livro Arte-educação: leitura no subsolo, organizado por Ana Mae Barbosa. Ott (2005 [1997]) propõe o ensino de crítica nos museus por meio do "sistema de interpretação Image Watching" que é composto por seis etapas sucessivas. Inicia-se com Thought Wacthing que é uma espécie de aquecimento, por meio de diferentes tipos de exercícios que desenvolvam uma atmosfera agradável para estimular a sensibilidade antes de partir para as outras etapas. Em seguida, passa-se às outras etapas obedecendo-se à seguinte ordem: descrevendo, analisando, interpretando, fundamentando e revelando (esse último realizado no ateliê/na escola).

Quando o Museu L diz que foi "necessário inúmeras alterações" para adequar a proposta de Ott à sua realidade, quatro questões vêm à tona. A primeira delas é sobre o artigo de Rizzi (2000) que aponta convergências do Image Watching com outras propostas de ensino da arte em museus, como a Triangular de Ana Mae Barbosa, assim como apresenta argumentações fundamentadas nas ideias de Michael Parsons (1998) quanto a não pertinência do sistema de Robert Ott em relação à interpretação da arte contemporânea. A segunda trata-se do posicionamento de Buoro (2002, p.32-3) sobre a proposta de Ott, ou seja, que embora ela tenha se baseado na abordagem dele em outro momento (mestrado), a sua prática com leitura de imagens, na pesquisa de doutorado, provou que a leitura não se dá de forma estanque - por meio de etapas. Isso ocorre porque, conforme a autora, "[...] o olho do leitor percorre, no tempo e no espaço, um caminho ao longo do qual são geradas significações e são construídos sentidos" (BUORO, 2002, p. 32). A terceira questão é a de se pensar até que ponto os educadores de museus estão atentos a propostas mais 
pertinentes à realidade brasileira, no que diz respeito ao ensino da arte em museus, ou estão desenvolvendo a partir de um embasamento teórico "[...] metodologias próprias que permitam a formação de um sujeito histórico-social que analisa criticamente, recria e constrói a partir de um referencial que se situa no seu patrimônio cultural tangível e intangível [...]", como afirma Studart (2004b, p.38). E a quarta revela na experiência vivida como mediadora em exposições de arte que as etapas, em forma sucessiva, mesmo que priorizem o diálogo, como a de Ott, não são possíveis em uma mediação entre os públicos e as obras de arte nas exposições, na qual o visitante também é agente e construtor desse processo.

Assim, quanto à teoria de Ott, ela se torna um tanto quanto discutível ao que se propõe, hoje, no trabalho de mediação entre os públicos e as obras de arte nas exposições. Por sua vez, as concepções de Paulo Freire $(2006$; 2008) e de Teresinha Franz (2003) são referências na contemporaneidade para o ensino da arte em museus por priorizarem o diálogo, as problematizações, a compreensão crítica, o respeito aos saberes das pessoas, assim como os seus níveis de compreensão e por terem também como princípio, no processo de ensinar e aprender, que quem ensina também aprende com o outro.

\section{Considerações finais}

Em relação às problemáticas que envolvem os setores educativos em alguns museus participantes da pesquisa, ressalta-se que elas estão, provavelmente, atreladas à falta de uma política cultural da instituição que priorize a educação. A questão também foi aqui discutida a partir do pensamento de alguns autores, como Studart (2004b, p.38) que deixa bem visível a referida condição assim enfatizando: "Não basta os educadores quererem dar um sentido claro ao seu trabalho, se este não fizer parte de uma política institucional". Nesse sentido, a falta de compreensão do que seja a adoção de políticas educacionais por parte de alguns atores museais, principalmente por aqueles que ocupam os cargos diretivos da instituição, impede que os setores educativos desenvolvam um trabalho de qualidade mesmo que eles se esforcem e procurem realizar diversas ações para atender os diferentes públicos.

Trabalhar com a potencialidade educativa de um museu de arte não é tarefa fácil, pois se sabe que não basta o museu apenas dispor de um setor educativo para que isto aconteça. É necessário, portanto, o envolvimento e comprometimento de todos os agentes museais para que diferentes públicos tenham um maior acesso ao patrimônio artístico-cultural por ele mantido. 
Desse modo, nota-se que o sentido da educação nos museus é muito mais abrangente. Não se restringe, portanto, ao atendimento do público escolar, como ainda pensam alguns gestores de museus. Essa postura de gestão de museu limita o potencial dos setores educativos, uma vez que não são chamados para as discussões pertinentes às políticas do museu, juntamente com os outros profissionais da instituição. Em vista disso, questiona-se: Como um museu exerce sua função educativa se não dialoga com os educadores?

\section{Referências}

ARANHA, Maria Lúcia de Arruda. História da educação. 2.ed. rev. e atual. São Paulo: Moderna, 1996.

ARAÚJO, Marcelo M.; BRUNO, Maria Cristina O. (Org.). A memória do pensamento museológico contemporâneo: documentos e depoimentos. Comitê Brasileiro do ICOM. [S.I.], 1995. Disponível em: <http://www.icom.org.br/memoria\%20do\%20pensamento\%20museologico4.pdf >. Acesso em: 29 abr. 2008.

BARBOSA, Ana Mae. A imagem no ensino da arte: anos oitenta e novos tempos. 6.ed. São Paulo: Perspectiva, 2005c.

Dilemas da arte/educação como mediação cultural em namoro com as tecnologias contemporâneas. In: BARBOSA Ana Mae. (Org.). Artel educação contemporânea: consonâncias internacionais. São Paulo: Cortez, 2005a.

BARBOSA, Ana Mae. Museus como laboratórios. In: Revista Museu - Artigos [2004]. Disponível em: <http://www.revistamuseu.com.br//artigos/art_.asp?id=3733>. Acesso em: 15 fev. 2008.

Tópicos Utópicos. 2.reimp. Belo Horizonte: C/ Arte, 2007.

BRASIL. Ministério da Cultura. Política Nacional de Museus: memória e cidadania. [Brasília]: MinC, 2003. Disponível em:

<http://www.museus.gov.br/downloads/Política_Nacional_de_\%20Museus.pdf>. Acesso em: 15 fev. 2008. 
BRASIL. Decreto $n^{\circ} 5.264$, de 5 de novembro de 2004 - Institui o Sistema Brasileiro de Museus e dá outras providências. In: MINISTÉRIO DA CULTURA. Política Nacional de Museus: relatório de gestão 2003-2006. [Brasília]: MinC/ IPHAN/ DEMU, 2006.

Lei $n^{\circ} 11.904$, de 14 de janeiro de 2009. Institui o Estatuto de Museus e dá outras providências. Disponível em:

<http://planalto.gov.br/ccivil_03/_Ato2007-2010/2009/Lei/L11904.htm>. Acesso em: 01 abr. 2009.

Lei $n^{0}$ 11.906/2009, de 20 de janeiro de 2009. Cria o Instituto Brasileiro de Museus - IBRAM, cria 425 (quatrocentos e vinte e cinco) cargos efetivos do Plano Especial de Cargos da Cultura, cria Cargos em Comissão do Grupo-Direção e Assessoramento Superiores - DAS e Funções Gratificadas, no âmbito do Poder Executivo Federal, e dá outras providências. Disponível em:

< http://www.planalto.gov.br/ccivil_03/_Ato2007-2010/2009/Lei/L11906.htm>. Acesso em: 18 jun. 2009.

BUORO, Anamelia Bueno. Olhos que pintam: a leitura da imagem e o ensino da arte. São Paulo: Educ/Fapesp/Cortez, 2002.

CHAGAS, Mário de Souza. Há uma gota de sangue em cada museu: a ótica museológica de Mário de Andrade. Chapecó: Argos, 2006.

DEWEY, John. Tendo uma experiência. In: Pragmatismo: textos selecionados. São Paulo: Abril Cultural, 1974. (Coleção Os pensadores).

FRANZ, Teresinha Sueli. Educação para a compreensão da arte. Florianópolis: Insular, 2001.

Educação para uma compreensão crítica da arte. Florianópolis: Letras Contemporâneas, 2003.

FREIRE, Paulo. Pedagogia da autonomia: saberes necessários à prática educativa. 33.ed. São Paulo: Paz e Terra, 2006.

Pedagogia do oprimido. 47.ed. Rio de Janeiro: Paz e Terra, 2008. 
HOOPER-GREENHILL, Eilean. Los museos y sus visitantes. Gijón: Trea, 1998.

LOURENÇO, Maria Cecília França. Museus acolhem o moderno. São Paulo: Edusp, 1999. MUSEUMS and Galleries Commission. Educação em museus. São Paulo: Editora da Universidade de São Paulo; Fundação Vitae, 2001. (Série Museologia, 3).

NASCIMENTO JUNIOR, José do. [Declaração sobre a lei que sanciona a criação do IBRAM]. In: COUTO, Sara Schuabb. Criação do Ibram - Sancionada a Lei que cria autarquia exclusiva para o setor museológico brasileiro. [Notícias do MinC - 21 de janeiro de 2009]. Disponível em: <http://www.cultura.gov.br/site/2009/01/21/presidente-lula-sancionacriacao-do- instituto-brasileiro-de-museus-ibram/>. Acesso em: 18 jun. 2009.

NASCIMENTO, Silvania Sousa do. O desafio de construção de uma nova prática educativa para os museus. In: FIGUEIREDO, Betânia Gonçalves; VIDAL, Diana Gonçalves. Museus: dos gabinetes de curiosidades à museologia moderna. Belo Horizonte: Argvmentvm; Brasília: CNPq, 2005.

OTT, Robert Willian. Ensinando crítica nos museus. In: BARBOSA Ana Mae. (Org.).

Arte-educação: leitura no subsolo. 6.ed. São Paulo: Cortez, 2005b.

RAMALHO E OLIVEIRA, Sandra Regina. Arte, Museu, Cultura e Educação. In: Ciclo "Museu, Educação e Cultura em Debate". 10 Encontro: Museu e formação cultural. Florianópolis: 25 maio 2006. (Texto impresso, não publicado).

ROSA BARBOSA, Maria Helena. Museus de Arte: desafios contemporâneos para a adoção de políticas educacionais. 2009. 256p. Dissertação (Mestrado em Artes Visuais) - Programa de Pós-Graduação em Artes Visuais, Universidade do Estado de Santa Catarina, Florianópolis, 2009.

SANTOS, Maria Célia T. Moura. Museu e educação: conceitos e métodos. In: Encontros museológicos: reflexões sobre a museologia, a educação e o museu. Rio de Janeiro: MinC/IPHAN/DEMU, 2008.

RIZZI, Christina. Contemporaneidade (mas não onipotência) do Sistema de Leitura de Obra de Arte Image Watching. Disponível em: <http://www.artenaescola.org.br/pesquise_artigos_texto.php?id_m=15>. Acesso em: 16 fev. 2009. 
STUDART, Denise Coelho. Conceitos que transformam o museu, suas ações e relações. In: DOSSIÊ CECA-Brasil. MUSAS - Revista Brasileira de Museus e Museologia/ Instituto do Patrimônio Artístico Cultural, Departamento de Museus e Centros Culturais. Vol.1, n.1, (2004). Rio de Janeiro: IPHAN, 2004a.

Educação em museus: produto ou processo?. In: DOSSIÊ CECA-Brasil. MUSAS Revista Brasileira de Museus e Museologia/ Instituto do Patrimônio Artístico Cultural, Departamento de Museus e Centros Culturais. Vol. 1, n.1, (2004). Rio de Janeiro: IPHAN, 2004b.

SUANO, Marlene. O que é museu. São Paulo: Brasiliense, 1986.

TORAL, Hernan Crespo. Seminário Regional UNESCO sobre a Função Educativa dos Museus, Rio de Janeiro -1958. In: ARAUJO, Marcelo M.; BRUNO, Maria Cristina O. (Org.). A memória do pensamento museológico contemporâneo: documentos e depoimentos. Comitê Brasileiro do ICOM. [São Paulo], 1995. Disponível em:

$<$ http://www.icom.org.br/memoria\%20do\%20pensamento\%20museologico4.pdf> Acesso em: 29 abr. 2008. 